\title{
THE HEART RATE OF BOYS DURING AND AFTER EXHAUSTING EXERCISE
}

\author{
By ERNST P. BOAS
}

(Received for publication October 31, 1930)

In most studies of the reaction of the heart rate to exercise, because of technical difficulties, observations have been made only before and after, but not during the exercise. The cardiotachometer (1) offers a simple means of following the heart rate continuously during periods of rest and violent activity. The action current of the heart is led from the body by two chest electrodes to an amplifier. The amplified current operates a relay system and an electromagnetic counter. With this instrument $I$ have studied the effect of exhausting exercise on the heart rates of 27 boys ranging in age from 9 to 15 years The wires connecting the subjects with cardiotachometer were 100 feet long, giving them a free range of activity. The exercise consisted in having them run back and forth in a long corridor until they were nearly exhausted, and then up a flight of stairs and down again. The duration of the exercise in the individual cases varied from 2 to 4 minutes with an average of $2 \frac{3}{4}$ minutes. Immediately following the exercise the subjects lay down on a bed where they remained until the end of the experiment. The severity of the exertion is shown by the fact that 10 of the boys fell asleep while resting afterwards.

Table 1 presents a summary of the findings. The average of the differences between standing and lying heart rates is 14.6. This corresponds to a difference of 15.7 found by Franke (2) in young men aged 20 to 22. A study of the level of initial pulse rates, of the difference between the rate standing and lying, and of the maximum rate, in relationship to the body habitus, the configuration of the heart as shown by $\mathrm{x}$-ray examination, and the blood pressure, reveals no correlations. In another series of normal cases I have been able to show a similar lack of correlation between heart rate and various bodily measurements (3). The boys were further classified according to a subjective estimate of their physical fitness, and no definite differ- 


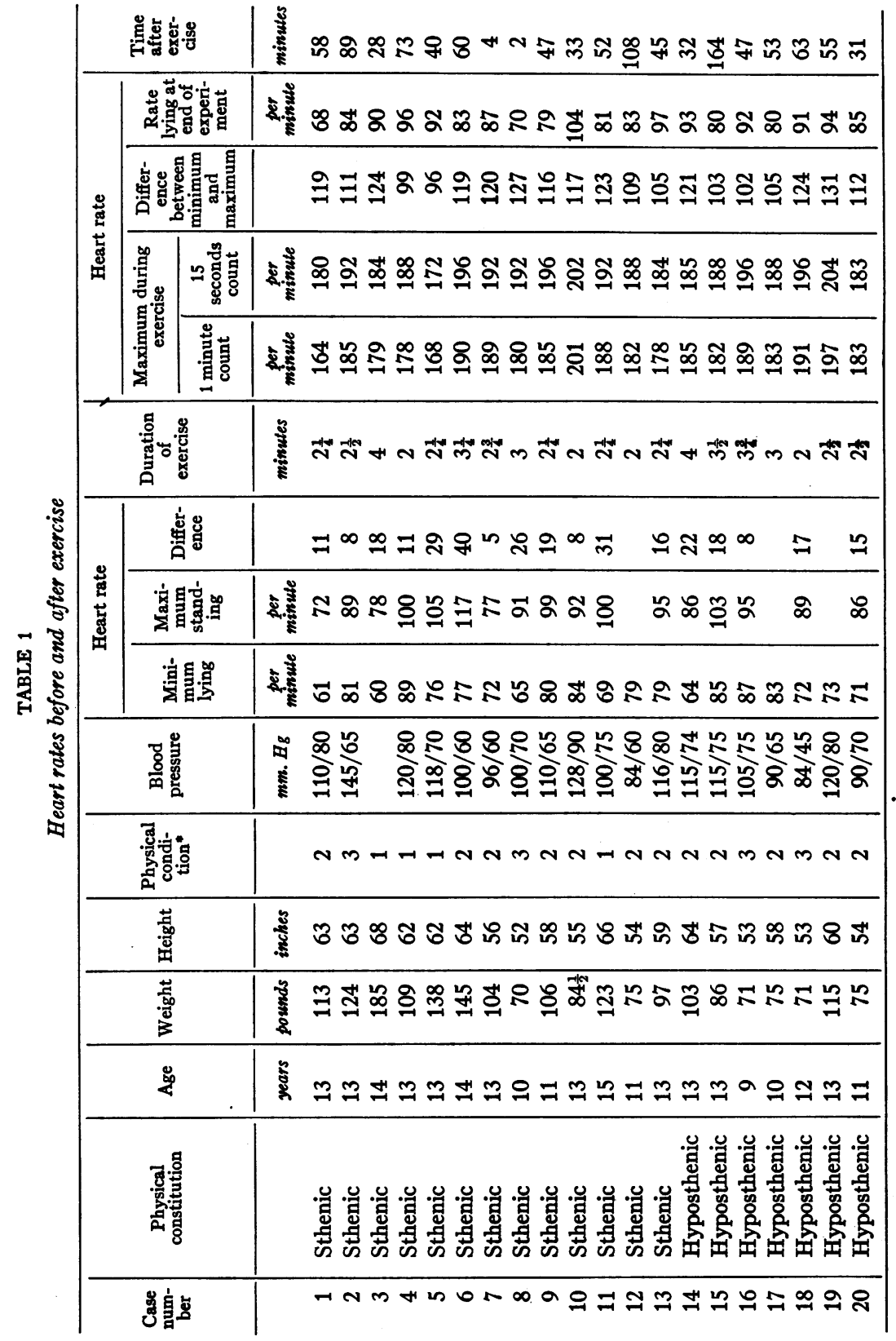




\begin{tabular}{|c|c|}
\hline ิㅗㅇ & in \\
\hline 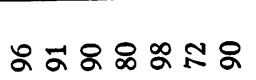 & $\stackrel{\infty}{\infty}$ \\
\hline 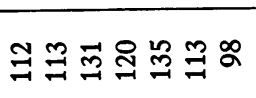 & बे \\
\hline 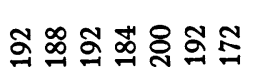 & $\ddot{8}$ \\
\hline 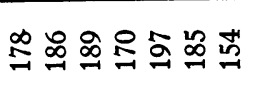 & $\stackrel{0}{0}$ \\
\hline 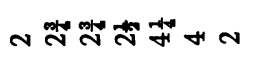 & $\stackrel{m}{N}$ \\
\hline สิ & $\stackrel{0}{ \pm}$ \\
\hline ヘேஃ & $\stackrel{0}{\infty}$ \\
\hline 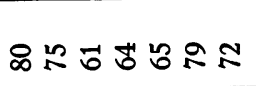 & Ti \\
\hline 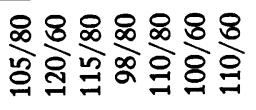 & \\
\hline$N M N M N M$ & \\
\hline 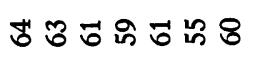 & \\
\hline ஃ ㅇㅇㅇ요융 & \\
\hline$\ddot{\rightarrow} \ddot{\sim}=\ddot{\sim} \leftrightarrows$ & $\stackrel{\infty}{\mathfrak{i}}$ \\
\hline 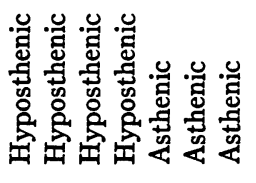 & 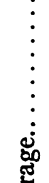 \\
\hline 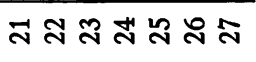 & $\sum^{\circ}$ \\
\hline
\end{tabular}


ence between the initial pulse rates, nor the level reached after exercise in the several groups was noted. Apparently the differences in the degree of training were too slight to manifest themselves in this way.

A striking feature was the very high maximum heart rate shown by most of the boys. The average maximum rate counted for a full minute occurred during the second minute of exercise and was 182.6 or two and one half times the resting rate. The average maximum rate, calculated from the highest rate observed in a fifteen second interval, was 190.0 and occurred on the average 97 seconds after the commencement of the exercise. In three cases the maximum rate was over 200 , namely 202, 204, and 200. In adults with severe work the maximum is given usually as from 160 to 170 (4), yet Henderson (5) has observed a rate of 246 after 30 minutes of exhausting exercises which resulted in collapse.

The absolute maximum heart rate attained does not depend on the initial resting pulse rate nor on the duration of the exercise. Others have shown that the rise in heart rate with exercise depends in part on the amount of work performed, and in part on the speed with which it is carried on. In the present study the boys were driven so far as possible to their physiological limit. The differences between them did not manifest themselves so much in the absolute height to which the heart rate rose, as by the time of occurrence of the maximum in each case. The boys who were exhausted after less than three minutes of exercise showed their maximum rate on the average 90 seconds after the beginning of exercise, while those who exercised more than three minutes before having to stop exhibited their maximum rate on the average 120 seconds after the beginning of exercise. This does not necessarily mean that the boys who exercised for longer periods of time were capable of greater exertion; some of them did not put forth the maximum effort of which they were capable until they were repeatedly urged and exhorted.

The increase in heart rate, that is the difference between the lying rate before exercise and the maximum during exercise was on the average 114.9. This increment in rate was the greater, the lower the initial heart rate. Thus those with an increment of over 121 had an average initial rate of 66.1 ; those with an increment between 110 and 120 had an average initial rate of 75 ; while those whose increment was 
less than 110 had an average initial rate of 81.2. Jaquet (4) has made a similar observation. Part of the acceleration induced by

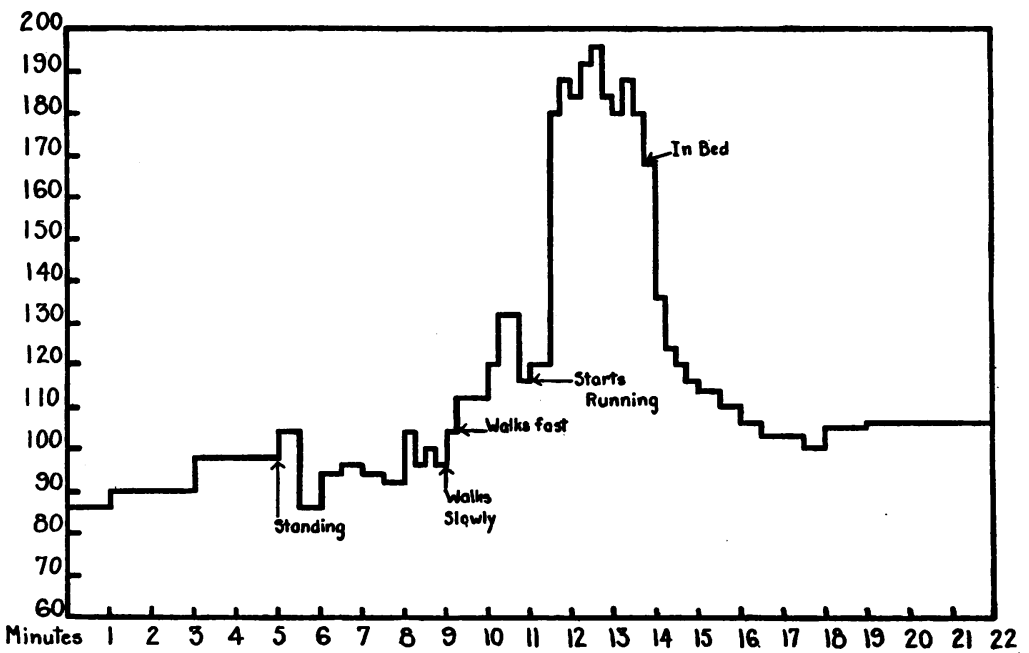

Fig. 1. Heart Rate during Exercise of Case 16

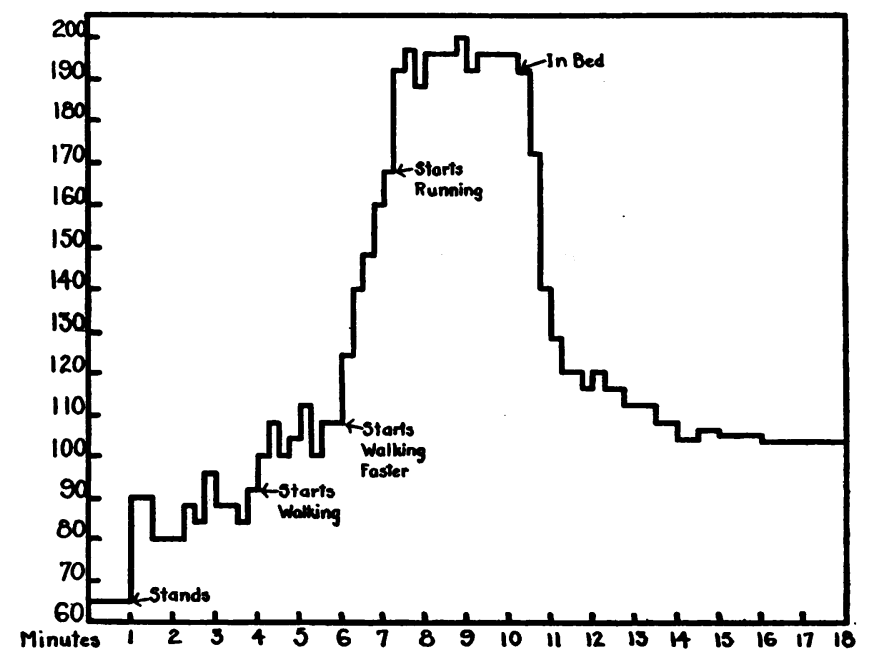

Fig. 2. Heart Rate during Exercise of CASE 25

exercise is covered by the high initial rate, which already represents a response of the heart to stimuli which raise the rate considerably above the basal. 
As has been found by Bowen and others $(6,7,8)$ the acceleration of the pulse begins immediately with exercise. This is well shown in the curves (fig. 1 and 2). Deceleration begins just as promptly, and

TABLE 2

Difference between heart rates (lying) before and after exercise

\begin{tabular}{|c|c|c|c|c|c|c|c|c|c|c|}
\hline \multirow{2}{*}{ Case number } & \multicolumn{10}{|c|}{ Time in minutes after end of exercise } \\
\hline & 1 & 2 & 3 & 4 & 5 & 10 & 15 & 30 & 60 & 90 \\
\hline 1 & 40 & 31 & 31 & 35 & & & 31 & 20 & 7 & \\
\hline 2 & 53 & 41 & 35 & 33 & 33 & 32 & 28 & 11 & 4 & 3 \\
\hline 3 & 84 & 57 & 45 & 38 & 38 & 41 & & 30 & & \\
\hline 4 & 42 & 25 & & 23 & 23 & 27 & 13 & 16 & & \\
\hline 5 & 36 & 28 & 22 & 24 & 23 & 22 & & 20 & 20 & \\
\hline 6 & 50 & 31 & & 25 & 26 & 23 & 23 & & 6 & \\
\hline 7 & 26 & 21 & & 15 & 19 & 24 & & 17 & 15 & \\
\hline 8 & 14 & 5 & 16 & 12 & 14 & 12 & & 14 & 11 & \\
\hline 9 & 39 & 20 & 25 & 20 & & 17 & 16 & 15 & 0 & \\
\hline 10 & 62 & 46 & & 39 & 35 & 33 & 24 & 22 & & \\
\hline 11 & 57 & 40 & & 29 & 29 & 30 & 33 & 26 & 12 & \\
\hline 12 & 57 & 41 & 30 & 25 & 22 & 25 & & 21 & 18 & 17 \\
\hline 13 & 47 & 34 & 33 & & 27 & & 29 & 24 & & \\
\hline 14 & 72 & 64 & 48 & 43 & 43 & 42 & 37 & 29 & & \\
\hline 15 & 31 & 28 & 22 & 21 & & 22 & & 16 & & \\
\hline 16 & 37 & 25 & 19 & 13 & 18 & 16 & 17 & 13 & 5 & \\
\hline 17 & 22 & 10 & 19 & 17 & 12 & 17 & 12 & 11 & 2 & \\
\hline 18 & & 62 & 37 & 27 & 28 & 28 & 21 & 20 & 19 & \\
\hline 19 & 60 & 51 & 51 & 49 & 41 & 37 & 37 & 35 & 24 & \\
\hline 20 & 68 & 29 & 28 & 29 & 29 & 32 & 33 & 16 & & \\
\hline 21 & 49 & 38 & 33 & 33 & 35 & 28 & 26 & 25 & 24 & \\
\hline 22 & 55 & 39 & & 32 & 35 & 35 & 34 & 22 & 18 & \\
\hline 23 & 48 & 46 & 40 & 43 & 44 & 45 & 42 & 37 & 33 & \\
\hline 24 & 61 & 46 & 32 & 29 & 28 & 30 & 30 & 20 & & \\
\hline 25 & 56 & 51 & 45 & 40 & 40 & 37 & 32 & & & \\
\hline 26 & 67 & 42 & & 33 & 27 & 27 & 21 & 16 & 3 & \\
\hline 27 & 67 & 41 & 34 & 34 & 40 & 39 & 33 & 21 & 20 & \\
\hline erage & 48.1 & 30 & 32.7 & 29.2 & 29.5 & 28.8 & 27.2 & 20.7 & 13.4 & 10 \\
\hline
\end{tabular}

within the first minute after exercise the major drop in rate is already completed.

Much attention has been paid by students of the cardiovascular effects of exercise to the time that elapses after exercise before the pulse rate returns to the resting figures. With light exercise this is 
accomplished in two minutes or less. After heavy work the pulse rate may remain high for many hours (4) and a rapid rate may even persist during sleep on the subsequent night (9). In only 5 of 18 of our boys who were followed for a full hour after the exercise did the pulse return to within 5 beats of the previous resting level at the end of an hour. In the whole group the average of the initial lying rates was 74.2 , and the average rate at the end of the experiment, which was on the average $\mathbf{5 1 . 5}$ minutes after the completion of the exercise, was 86.8. Thus after almost an hour the heart rate was on the average 12.6 points higher than before the exercise.

In table 2 the differences between the heart rates (lying) before the exercise, and in successive minutes after the exercise are recorded. There is a rapid drop in rate during the first two minutes after exercise, and then a very slow drop of about ten beats in the next half hour, and 7 beats in the succeeding half hour.

We found, as have others, that in the boys who were in better physical condition the reduction in heart rate after exercise occurred a little more rapidly. The duration of the exercise was without visible effect. The closeness with which the heart rate at the end of the experiment approached the rate before exercise was definitely influenced by the level of the original rate. Thus those boys in whom the difference in rate before and after exercise was 15 or less had an average initial resting rate of 77 ; while in those in whom the difference was over 15 the original rate was 71 . The speed with which the heart rate returned to normal was not influenced by the maximum rate that had been reached during the exercise.

\section{SUMMARY}

Slowing of the heart rate after exercise is so rapid that a true picture of the effect of exercise on the curve of heart rate can be gained only by recording the rate continuously during exercise. Such a study, carried out with the cardiotachometer, on 27 boys subjected to exhausting exercise showed an average maximum rate during exercise of 190. The highest recorded rate was 204. Although the major drop in rate is completed within one minute after exercise, in most cases, the rate is still considerably above the resting level at the end of an hour. 


\section{BIBLIOGRAPHY}

1. Boas, E. P., Arch. Int. Med., 1928, xli, 403. The Cardiotachometer. An Instrument to Count the Totality of Heart Beats over Long Periods of Time.

2. Franke, K., Ztschr. f. d. ges. Anat. Abt. 2 Ztschr. f. Konstitut. lehre 1928, xiii, 575. Über die Variabilität der Puls- und Atemzahl bei Kreislaufgesunden, körperlich gut entwickelten jungen Männern.

3. Boas, E. P., and Goldschmidt, E. F., Klin. Wchnschr., 1930, ix, 1115. Studien mit dem Kardiotachometer über Frequenz und Rhythmus des Herzschlags.

4. Jaquet, A., Muskelarbeit und Herztätigkeit, Basel, 1920, p. 9.

5. Henderson, Y., Haggard, H. W., and Dolley, F. S., Am. J. Physiol., 1927, lxxxii, 512. The Efficiency of the Heart, and the Significance of Rapid and Slow Pulse Rates.

6. Bowen, W. P., A Study of the Pulse Rate in Man as Modified by Muscular Work. Contributions to Medical Research Dedicated to V. C. Vaughn, Ann Arbor, Mich., 1903.

7. Bainbridge, F. A., The Physiology of Muscular Exercise. London, 1919, p. 69.

8. Grünbaum, R., and Amson, H., Deutsch. Arch. f. klin. Med., 1901, lxxi, 539. Ueber die Beziehungen der Muskelarbeit zur Pulsfrequenz.

9. Moritz, F., Münch. Med. Wchnschr., 1915, lxii, 1. Ueber klinische Zeichen beginnender Herzschwäche. 